\title{
Design and Implementation of a Transformer Less Single-Phase Symmetrical Z- Source Heric Inverter with Reduced Leakage Currents for PV Systems
}

\author{
B. Prasanth (Research Scholar) ${ }^{1}$, G. Karthikeyan ${ }^{2}$, B.Senthilkumar ${ }^{3}$, K. Karthi ${ }^{4}$ and P. Rajesh kumar ${ }^{5}$ \\ $1,3,4,5$ \\ V.S.B. Engineering College, Karur \\ 2 Sona College of Technology, Salem
}

\begin{abstract}
A transformer less single-stage symmetric Z-source HERIC inverter including low spillage flows is proposed right now. It is an endeavor to use the Highly Efficient and Reliable Inverter Concept (HERIC) and an impedance source (Z-source) system to keep up a steady normal mode voltage and consequently low spillage flows in PV applications. The proposed inverter successfully eases the spillage current issue by expelling high-recurrence segments for the regular mode voltage. A lift DC/DC converter is ordinarily embraced in such frameworks, prompting a moderately low productivity, particularly when the PV voltage is low. Answers for this test are to adjust tweak techniques or exchanging designs and along these lines ease the variety of the regular mode voltage. The activity guideline of the proposed inverter is depicted together with its control system. The symmetric Z-source HERIC inverter requires dynamic switches. By and by, the activity recurrence of the switches is the line recurrence, prompting insignificant misfortunes.
\end{abstract}

\section{KEYWORDS: HERIC Inverter, Spillage Current, DC-DC Converter}

\section{I.INTRODUCTION}

The improvement of PV frameworks is mostly effectiveness and unwavering quality driven. Utilizing the transformers can make the association between the lattice and the PV cluster eliminated. The transformer less inverter with low spillage flows can take care of the issue in network associated PV frameworks, especially in low-power single-stage frameworks. So different transformers less inverter topologies have been proposed to meet the purpose of decreasing spillage flows by specialists around the framework. Inverters can be arranged dependent on electrical disengagement between PV boards and network as Low Frequency (LF) transformer inverters, High Frequency (HF) transformer inverters and transformer less inverters. The effectiveness is expanded by about. Maintaining a strategic distance from the transformer prompts two significant issues DC flows getting infused into the lattice and ground spillage current coursing through parasitic capacitance, arrives at the framework.

The DC infusion causes a few issues like center immersion of circulation transformers, throbbing torque in electrical machines, exactness issues spillage flow causes EMI issues and wellbeing issues to working faculty. The photovoltaic (PV) frameworks work in dispersed age applications in two distinct arrangements: independent and lattice associated. In the two applications normally some basic parts are utilized including PV boards, inverters and vitality stockpiling gadgets. The vitality stockpiling gadgets for the most part are utilized as strong state redox stream batteries alongside mixture energy unit power age frameworks. The inverters are key parts empowering the mix of PV boards and vitality stockpiling frameworks to these half and half vitality frameworks. The PV power framework has gotten progressively 

two significant capacities secluding the photovoltaic board from the network, and forestalling the receptive force trade between the channel inductors and capacitors during the zero voltage state, in this way expanding proficiency. Likewise the spillage current way is cut off too. It works unobtrusively without any discharges and requires little upkeep. Conveyed matrix associated PVs are assuming an inexorably huge job as an electric stock asset and as an essential piece of the electrical network. The spillage current scientifically and has proposed another topology to limit spillage current. The proposed model comprises of parasitic capacitance framed between positive, negative and mid-purpose of the inverter legs with the ground, the channel inductances, line impedances, differential mode capacitances in EMI channel, differential and regular mode inductances. The voltage reference is taken as the negative terminal of sun powered boards.

A typical mode identical model is inferred at medium recurrence go. From the model the creators recommend that, suitable PWM methods can be intended to accomplish steady normal mode voltage. Likewise, circuit parameters might be modified to get steady basic mode voltage n PV applications a transformer is regularly used to give galvanic disengagement and voltage proportion changes. Be that as it may, these ordinary iron and copper-based transformers increment the weight/size and cost of the inverter while lessening the proficiency and force thickness.

As a rule, the expense and size are two restricting components for completely incorporating the inverters inside the network. One potential answer for lessen the inverter's size and cost is to use the transformer less lattice associated inverters. Subsequently dispensing with transformers is an extraordinary advantage to additionally improve the general framework productivity and lessen the size and weight. However, the disposal of the transformer from the inverter's structure, presents the probability of the ground spillage current, The effectiveness right now altogether diminished, not just in view of the misfortunes in the transformer yet in addition in view of the extra influence organizes that must be included the influence change process. Since the effectiveness is one of the most significant issues in a PV framework, transformer less inverters has developed to alleviate the issues of the galvanic segregated frameworks. The converter is utilized to help up the got dc input voltage to alluring worth.

\section{II.SOFTWARE DESCRIPTION}

The proposed framework that will be portrayed right now done utilizing the Mat Lab Simulink model. So as to get the ideal yield, the recreation circuit has been planned in Mat Lab programming by utilizing the individual parts that is available in the Mat Lab Simulink. This reenactment circuit will be depicted in detail underneath. MATLAB an elite language for specialized processing incorporates calculation, perception, and programming in a simple to-utilize condition where issues and arrangements are communicated in commonplace numerical documentation. It is a prototyping situation, which means it centers on the simplicity of improvement with language adaptability, intelligent investigating, and different comforts ailing in execution arranged dialects like $\mathrm{C}$ and FORTRAN. While Mat lab may not be as quick as $\mathrm{C}$, there are approaches to bring it closer. We need to invest less energy aggregate from creating, troubleshooting, running, and until getting results.

It is an intelligent framework whose essential information component is an exhibit that doesn't require dimensioning. It permits you to tackle numerous specialized processing issues, particularly those with lattice and vector definitions, in a small amount of the time it would take to compose a program in a scalar non intuitive language, for example, $\mathrm{C}$ or FORTRAN. The name MATLAB represents network research facility. MATLAB was initially composed to give simple access to framework programming created by the LINPACK and EISPACK ventures. Today, MATLAB motors join the LAPACK and BLAS libraries, implanting the best in class in programming for network calculation. It has developed over a time of years with contribution from numerous clients. In college situations, it is the standard instructional apparatus for initial and propelled courses in arithmetic, building, and science. In industry, MATLAB is the device of decision for high-profitability research, improvement, and examination. 

most clients of MATLAB, tool compartments permit you to learn and apply particular innovation. Tool compartments are thorough assortments of MATLAB capacities (M-documents) that stretch out the MATLAB condition to tackle specific classes of issues. You can add on tool stash for signal handling, control frameworks, neural systems, fluffy rationale, wavelets, recreation, and numerous different regions.

\section{III.CONVENTIONAL SYSTEM}

The conventional single-phase grid connected PV inverter systems have a high-frequency transformer that comprises DC-DC converter for adjusting the DC input voltage and have a linefrequency transformer for separating the PV panels from the load or grid. However, when the singlephase transformer less grid-connected PV inverters does not have transformers or other stages, the major problem of the PV inverter still has leakage current. The leakage current happens when the PV inverter switches action, and it happens fluctuations in the potential waveform between the PV panels and the ground. The PV inverter injects leakage currents through the ground path to parasitic capacitances on both DC side and AC side.Furthermore, due to increased penetration of low-power single-phase PV systems in residential applications, a single-stage single-phase grid-connected PV system with a nonlinear control strategy is proposed in this dissertation. Unlike to the single-phase system, the single-phase system includes a novel method to mitigate the double line frequency current ripple of the PV array, which is the major drawback of the single-phase PV inverter. Moreover, based on the preceded work, the nonlinear controller is combined with adaptive control to estimate the unknown disturbances that physically could appear in the circuit and affect the performance of the system.

\section{IV.PROPOSED SYSTEM}

A single-phase symmetrical Z-Source HERIC inverter and the corresponding modulation strategy is implemented. Furthermore, impedance source networks cannot be directly connected in between the PV panels and the transformer less topologies due to the required through operation. In this method the challenge are to modify modulation strategies or switching patterns and therefore alleviate the variation of the common mode voltage. To eliminate the leakage current induced by the common mode voltage, the clamping topology can be adopted to hold the common-mode voltage on a constant value in the freewheeling period. A full-bridge inverter topology with constant common-mode voltage. The proposed $\mathrm{Z}$ source HERIC inverter features a constant common mode voltage without affecting the performance of the impedance source network, and thus the merit of low leakage currents remains

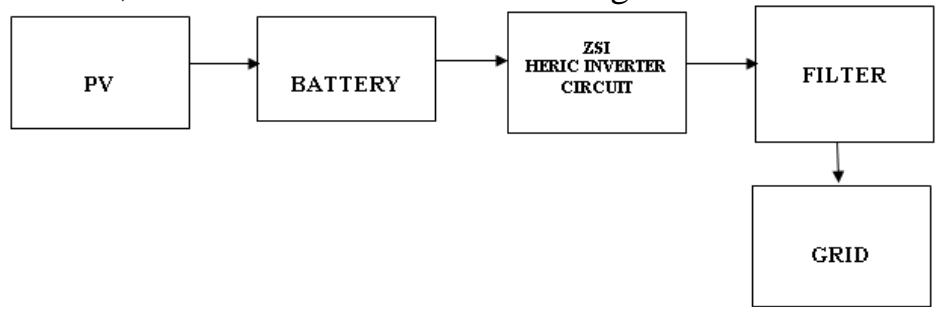

Figure 1: Proposed Block Diagram

$>$ The sunlight based illumination level is constrained by fluctuating the short out current in the trademark condition.

$>\mathrm{A}$ DC - DC converter is normally used to change over from one DC voltage level (frequently unregulated) to another controlled DC voltage level. Contingent upon the converters setup, the subsequent yield voltage can be a stage - up or step - down capacity of the information voltage, and can show up as a positive or negative voltage to the heap.

$>$ The customary PWM inverter has used to control the yield DC voltage. Anyway the Z-source inverter has two autonomous control opportunities; shoot through obligation cycle and balance list. 
Journal of University of Shanghai for Science and Technology

The Z-source inverter gives similar highlights of a DC-DC helped inverter.(single arrange less mind boggling and progressively compelling.

\author{
ADVANTAGES \\ $>$ Lower current stress on inductors and diode. \\ $>$ Suppress inrush current at start up. \\ $>$ Higher modulation index with lower component voltage stresses. \\ $>$ No of turns and size of the input inductor can be reduced.
}

\title{
V.SYMMETRIC Z-SOURCE HERIC DERIVED TOPOLOGIES
}

HERIC inverters have topological derivations and are connected to the symmetrical Z-source network with minor modifications while still maintaining constant CM voltage. Symmetrical Z-source HERIC inverters with an active clamping and passive clamping path are presented. Their operation principles are similar to that of the symmetrical Source HERIC inverter. The clamping point is beneficial to a more stable CM voltage, although two extra DC capacitors are adopted. These two solutions have their own pros and cons. In terms of power losses, the active clamping solution features lower conduction losses because only one active clamping switch is used, while two clamping diodes are used in the passive solution. However, the passive solution is easier to use and more robust because no extra isolated gate driver is needed. The use of these two solutions depends on the requirement of the application.

\section{VI.SIMUATION AND EXPERIMENTAL RESULTS}

Hence figure shows the schematic of the symmetrical Z-source HERIC inverter system, which consists of a symmetrical Zsource network, a HERIC inverter, and an L-filter network.In the case of a unity power factor operation, two sinusoidal signals with $180^{\circ}$ phase difference (yellow and green) for the AC output and a DC signal (blue) for the shoot-through state are utilized as the modulation signals, the inverter has five switching behaviors denoted as Mode 1 to Mode 5.The symmetric Z-source network is built by using two STW28N65M2 MOSFET as diodes, two Bourns 1140 inductors and two Nichicon UCP2G121MHD capacitors. The HERIC inverter is constructed by using six STW28N65M2 MOSFETs.

It is observed figure that the proposed symmetrical Z-source HERIC inverter presents a CM voltage with the least variation among these four inverters, and thus the corresponding leakage current is the lowest. These results verify the concept to reduce the leakage current with the proposed solution. For a quantitative analysis, a $220-\mathrm{nF}$ capacitor is connected between point $\mathrm{O}$ and the ground as an emulated capacitor. The root mean square value of the capacitor is recorded as an indicator representing the suppression of leakage currents. The measured results with different output power of the simulation models are shown in Figure. It is observed in Figure that the proposed symmetrical Z-source inverter has better performances compared to the other three configurations. It is further seen in Figure that an approximately 95\% reduction of the leakage current (root mean square) compared with that of the conventional $\mathrm{Z}$-source $\mathrm{H}$-bridge inverter. The quantitative comparison results further confirm the proposed solution and show the superiority in terms of leakage current suppression in transformer less PV applications. 


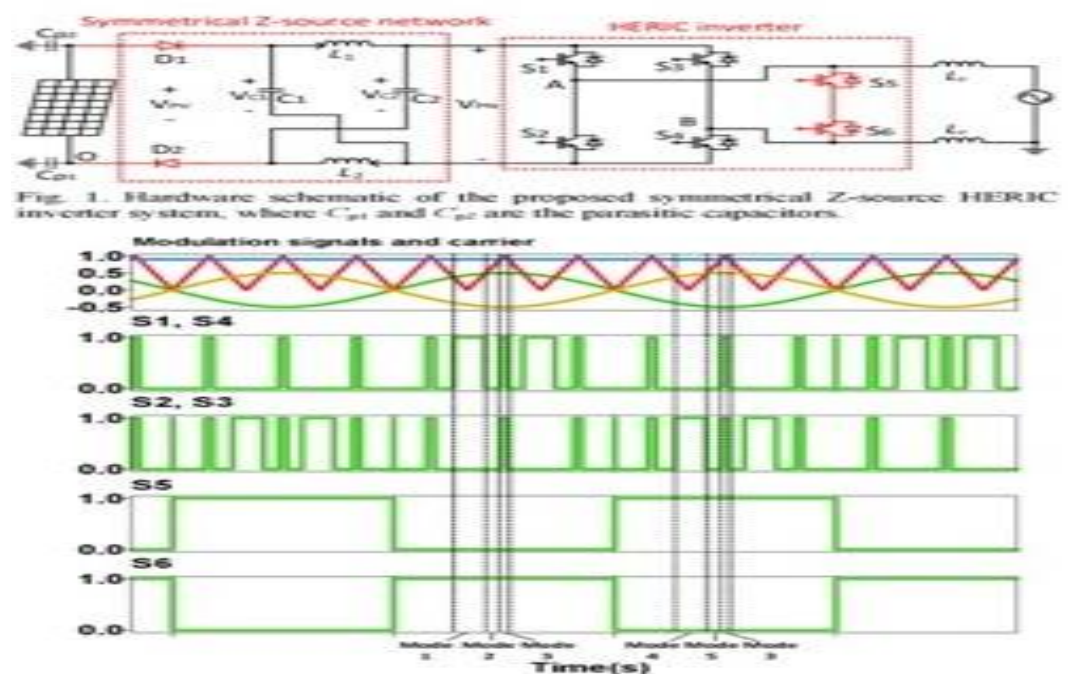

Figure2 :Heric inverter Setup

The operation conditions are shown as follows: input voltage Vin is $60 \mathrm{~V}$, and the maximum DClink voltage VPN is approximately $280 \mathrm{~V}$. Hence, the inverter output voltage is set as $110 \mathrm{~V}$ (root mean square), and the output power is $100 \mathrm{~W}$ with a resistive load, in which the two filter inductors Lr are of $3.3 \mathrm{mH}$. Comparisons with an Z-source H-bridge inverter, a symmetrical Z-source H-bridge inverter, and an Z-source HERIC inverter are carried out.

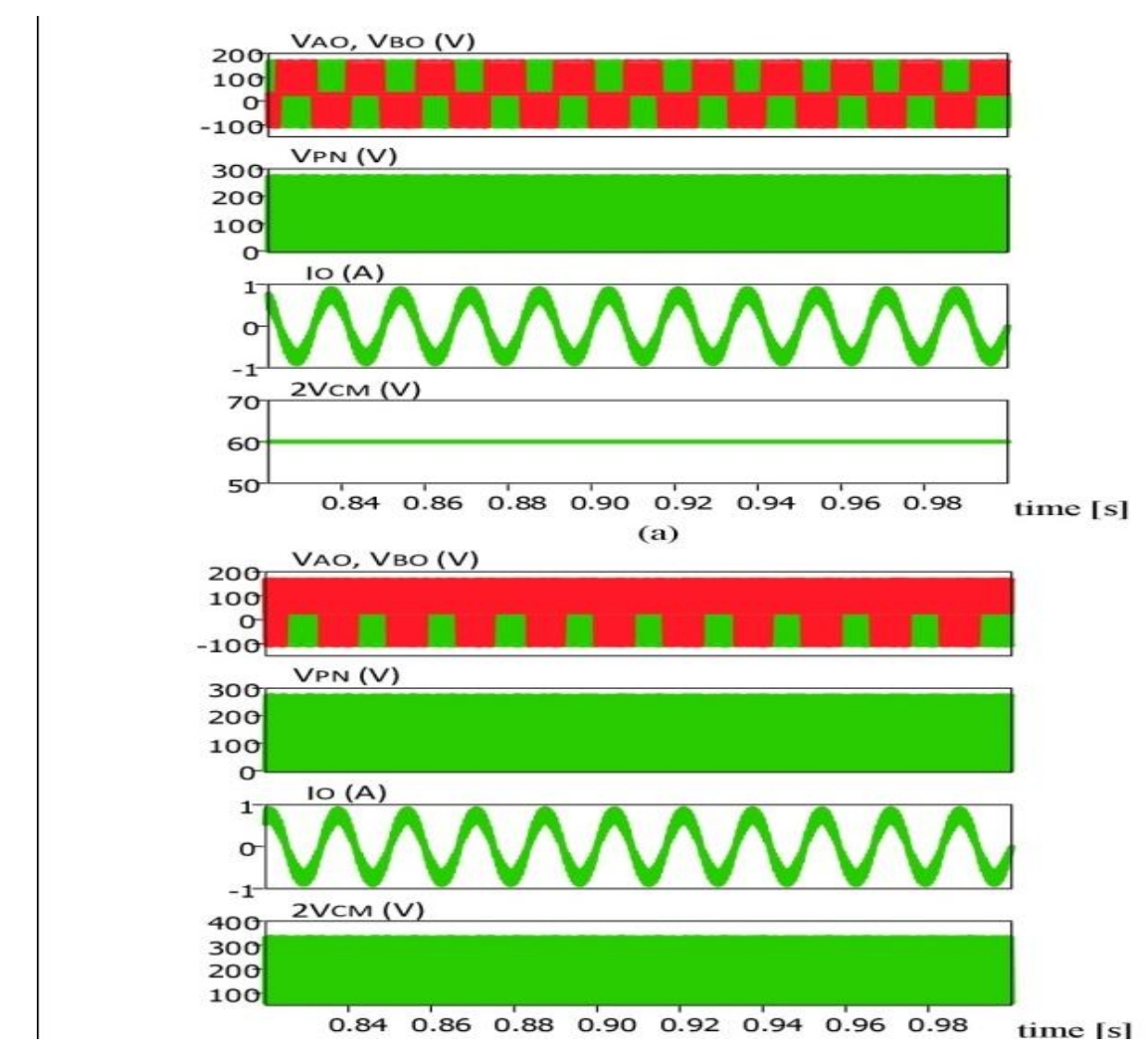

Figure3 :Simulation Results 


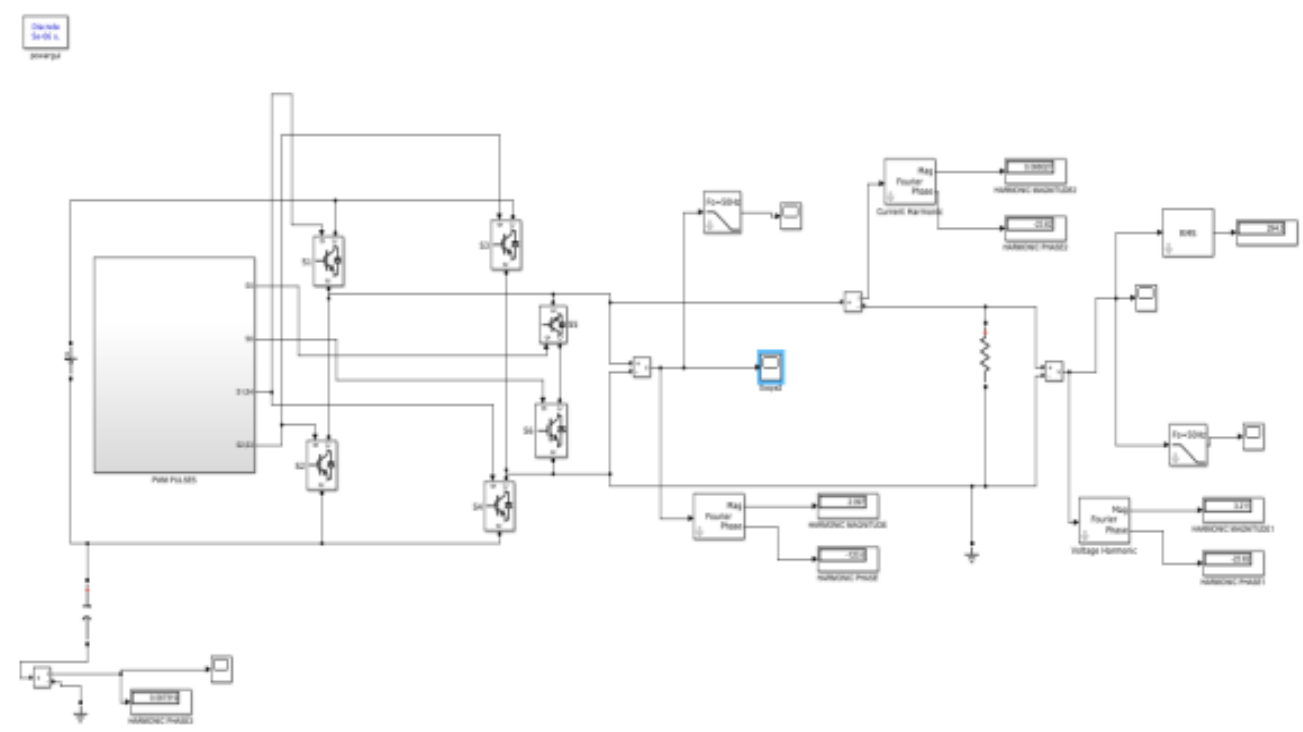

Figure 4: Simulink Model

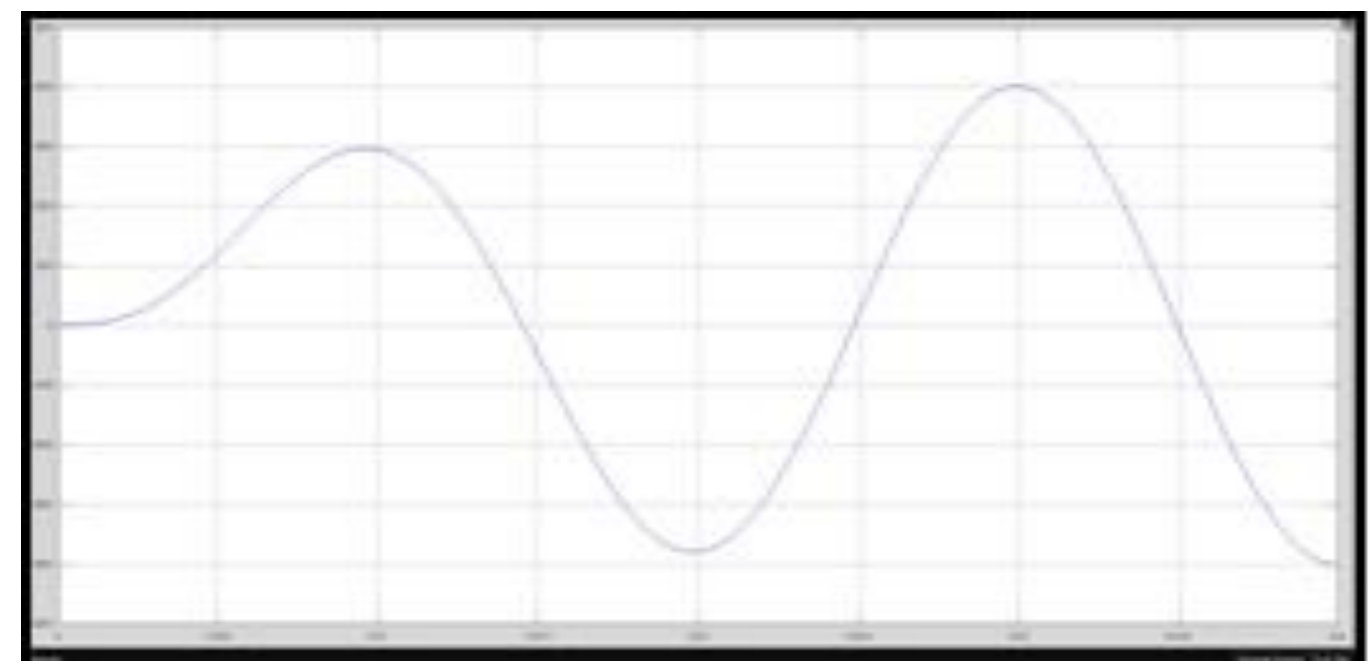

Figure5 :Output Voltage

\section{VII.CONCLUSION}

Even Z-source HERIC inverter has been displayed and created right now. The even Z-source HERIC variations were additionally determined by including the dynamic and detached bracing way. The regular mode voltage (in a roundabout way mirrors the spillage flows) for the proposed inverter has likewise been examined in proposed technique. The examination shows that the even Z-source HERIC inverter keeps up a steady basic mode voltage during activity. In this manner, the yield will lessen the spillage flows are low, and lower sounds as reduced. The impedance source based inverters, including the proposed even Z-source HERIC inverter. 


\section{REFERENCES}

1. Patel, R. R., Patti, S. P., Patti, S. D., \&Mulla, A. M. "Designing Of Z-source inverter for photovoltaic system using MATLAB/SIMULINK". International Conference on Circuit, Power and Computing Technologies (ICCPCT). doi:10.1109/iccpct.2017.

2. ELAMURUGAN P, PRABHU P, JAINULAFDEEN A, \& SIVA K, "Active Vibration Control of Rotating Machines",Solid State Technology 63 (2), 5205-5217,2020

3. SHUO LIU, BAOMING GE, "A Novel Indirect Quasi-Z-Source Matrix Converter Applied To Induction Motor Drives "IEEE ENERGY CONVERSION CONGRESS AND EXPOSITION, PP. 2440 - 2444, YEAR 2013.

4. OMAR ELLABBAN, HAITHAM ABU-RUB, " A Quasi-Z-Source Direct Matrix Converter Feeding A Vector Controlled Induction Motor Drive" IEEE JOURNAL OF EMERGING AND SELECTED TOPICS IN POWER ELECTRONICS, PP. 339 - 348,YEAR 2015.

5. ELAMURUGAN, P, VINOTH BRESNAV K, ABIRAMI, D, \&SUHIRDAM KG, "Automatic Material Segregation Using PLC” International Journal of Engineering and Technology (UAE) 7 (2), 376-380,2018.

6. Kshirsagar, N., Debre, P. D., Kadu, A., \&Juneja, R. "Design of three phase Z-source inverter for solar photovoltaic application". International Conference on Innovations in Information, Embedded and Communication Systems (ICIIECS). doi:10.1109/iciiecs.2017.

7. MISS. MONA MAHAJAN, MR. NIKHIL WANJARI, "Review Paper On A Quasi-Z-Source Direct Matrix Converter" INTERNATIONAL CONFERENCE ON RECENT TRENDS IN ENGINEERINGSCIENCE AND TECHNOLOGY, PP. 2321-8169, YEAR 2017.

8. ELAMURUGAN P, JAINULAFDEEN A ,VARATHAN G, SIVAKUMAR R \&RAGUL S, "Mixture Ratio Control in Cement Industry Using PLC and SCADA" Tierärztliche Praxis 39 (11), 160172,2019

9. ASHISH BHAVSSAR1 \& PRABODH KHAMPARIYA, "Induction Motor Fed by Matrix Converter, Modeling, Simulation and Implementation "IMPERIAL JOURNAL OF INTERDISCIPLINARY RESEARCH, PP. 2454-1362, YEAR 2017.

10. ELAMURUGAN P, UMAMAHESHWARI K, RAGUL $S$ \&PRASANTH B, SIVAKUMAR R, "Traffic Light Pre-Emption Control System for Emergency Vehicles, ", Journal of University of Shanghai for Science and Technology 22 (11), 601-605,2020.

11. NOZADIAN, M. H. B., EBRAHIMZADEH, F., BABAEI, E., \&ASL, E. S. "Current-fed switched Zsource inverters". 14th International Conference on Electrical Engineering/Electronics, Computer, Telecommunications and Information Technology (ECTICON). doi:10.1109/ecticon.2017. 
12. ELAMURUGAN, $P$ \&SIVA, $K$ "Design and Implementation of Multivariable Controller for Fluid Catalytic Cracking Unit in Petroleum Refinery"Asian Journal of Research in Social Science and Humanities 7 (1), 62-72,2017.

13. ELAMURUGAN P, RAGUL S, JAINUL AAFDEEN,VARATHAN G, "Controlling of Reactor Temperature and Re-Generator Temperature in FCCU,"International Journal of Innovative Technology and Exploring Engineering ,8(10), 2332-2338,2019. 